\title{
"Shall We Play a Game?": Improving Reading Through Action Video Games in Developmental Dyslexia
}

\author{
Sandro Franceschini ${ }^{1,2} \cdot$ Sara Bertoni $^{1} \cdot$ Luca Ronconi $^{1,2}$ - Massimo Molteni $^{2}$. \\ Simone Gori ${ }^{2,3}$ - Andrea Facoetti ${ }^{1,2}$
}

Published online: 28 September 2015

(C) Springer International Publishing Switzerland 2015

\begin{abstract}
Impaired linguistic-phonological processing is the most accepted explanation of developmental dyslexia (DD). However, growing literature shows that DD is the result of the combination of several neurocognitive causes. Visual attention and magnocellular-dorsal (MD) pathway deficits are now considered causes of DD. Interestingly, a large portion of literature showed that action video games (AVG) are able to improve attentional and perceptual skills in typical readers. Consequently, employing AVG trainings in individuals with DD could improve attention and perception, resulting in better reading skills. The aim of our review is to show the benefits of the AVG training on DD through the changes in the neurocognitive functions at the basis of learning to read. Since visual attentional and MD dysfunctions can be diagnosed in infancy, our review paves the way for possible early prevention programs that could use AVG training.
\end{abstract}

This article is part of the Topical Collection on Developmental Dyslexia

Simone Gori

simone.gori@unibg.it

Andrea Facoetti

andreafacoetti@unipd.it

1 Developmental and Cognitive Neuroscience Lab, Department of General Psychology, University of Padua, via Venezia 8, 35131 Padua, Italy

2 Child Psychopathology Unit, Scientific Institute, IRCCS Eugenio Medea, via don Luigi Monza 20, 23842 Bosisio Parini, Lecco, Italy

3 Department of Human and Social Sciences, University of Bergamo, Piazzale S. Agostino 2, Bergamo 24129, Italy
Keywords Selective attention - Attentional rehabilitation . Reading disability $\cdot$ Dyslexia remediation $\cdot$ Video games training $\cdot$ Perceptual learning $\cdot$ Developmental disorders . Developmental dyslexia $\cdot$ Linguistic-phonological processing $\cdot$ Action video games $\cdot$ Magnocellular-dorsal pathway deficits

\section{Introduction}

Difficulties in reading acquisition are the most common neurodevelopmental disorder across cultures (about $10 \%$ of children) and are present in both alphabetic and logographic languages. This disorder is called developmental dyslexia [1].

The etiology of developmental dyslexia (DD) is complex and hotly debated, and the main causes are attributed to auditory-phonological, visuo-attentional and procedural learning deficits $[2,3 \bullet, 4 \bullet, 5 \bullet, 6 \bullet]$. Often, DD presents important comorbidity with other disorders such as, for example, developmental dyscalculia, dysgraphia, attention deficit hyperactivity disorder (ADHD), specific language impairment (SLI) and speech-sound disorder [7].

The abilities to extract visual information and combine that with auditory information are considered at the basis of reading acquisition [8]. The act of reading must be sufficiently fast to operate within the constraints of limited capacity and rapid decay of the information processing [9].

The lack of synchronization among auditory and visual processes could lead to weak consolidation of letter-tospeech sound integration $[10 \bullet 11,12 \cdot]$.

A mild impairment in the magnocellular-dorsal (MD) visual pathway, with or without a corresponding deficit in the auditory system, has been hypothesized as possible core deficit in DD $[4 \cdot, 5 \bullet, 6 \bullet, 13-17]$. 
The parieto-frontal attentional network is included in the MD pathway $[18,19]$. Several studies showed perceptual and attentional deficit in DD (e.g. [2, 20-34, 35•, 36-42, 43•, 44-51, 52•, 53•, 54, 55•, 56•, 57•]). Efficient abilities in extraction and selection of the visual information allow to create stronger visual object representations [8, 58-62].

This short overview showed that neurocognitive developmental dysfunctions in DD may not be limited to the linguistic brain areas, and that several neurocognitive functions are related to DD [50].

Nevertheless, currently, the most common approach to DD remediation is the direct intervention with explicit, systematic instruction on letter-to-speech sound integration [63]. These treatments are highly demanding, and the cognitive processes underling the reading improvements remain unclear [1, 64]. Moreover, a relevant problem is the dropout during the training [1]. Unfortunately, and unsurprisingly, DD is associated with less literacy-related activities, and children with DD probably feel much more pressed in reading and learning compared with typical readers. This could explain a high tendency in individuals with DD to spend time at computer and watching TV [65]. These behaviours aggravate their reading problems, leading to a vicious circle [65].

Considering that the amount of time spent in playing video games is associated with poorer academic performance $[66,67]$, we can introduce our idea about the use of action video game (AVG) to improve reading abilities.

In the next sections, we make a connection between two research fields that are apparently far from each other. We review the literature about the perceptual and attentional skills that are usually compromised in people with DD, and the amelioration of the same functions that has been found studying AVG players or the effects of the AVG training.

\section{Action Video Games}

Video games present a big variety of platforms and genres, which can produce different effects on information processing (for a review, see [68•]). Little or nothing can be inferred by merely knowing that an individual plays video games [69].

Here, we will analyse mainly the effects of the most studied type of video games, the so-called AVG. This specific kind of games share a set of qualitative features, including extraordinary speed (both in terms of very transient events and in terms of the velocity of moving objects), a high degree of perceptual, cognitive, and motor load in the service of an accurate motor plan (multiple items that need to be tracked and/or kept in memory, multiple action plans that need to be considered and quickly executed typically through precise and timely aiming at a target), unpredictability (both temporal and spatial) and an emphasis on peripheral processing [70]. As for sport or music, an AVG player is a person that had played at least
4 days per week for a minimum of $1 \mathrm{~h}$ per day for the previous 6 months [71].

To establish the effects of AVG, intervention studies are conducted by training with AVG those individuals who do not play video games. Usually, these trainings have a duration from 10 to $50 \mathrm{~h}$ spaced over the course of weeks or months [69].

Perceptual and attentional abilities have been extensively studied in AVG players, and in trained non-video gamers (see $[70,72]$ for reviews). These findings will be reconsidered in the perspective of AVG as a possible training tool for DD.

\section{Visual Spatial Attention in Dyslexia and Action Video Games}

One of the most relevant neurocognitive functions involved in reading is probably what has been termed "spotlight of attention" [73]. Attention orienting is often compared with a "spotlight" that moves to a specific region in the visual space, improving information processing in the attended area at the expense of other locations (see $[18,74]$ for reviews).

In a visual search task (Fig. 1), targets of interest rarely possess unique features that help them to pop out from among distracting elements in a scene.

The attentional spotlight helps to recognize one item at the time and to "bind" the different attributes of each object such as its form, color, depth, motion and size [17]. In reading, the same mechanisms are used to sweep the spotlight of attention serially over the letters of a word during the periods of fixation. Reading disabled children presents slower search times than typical children when the search involves increasingly larger number of distractors (e.g. [29, 75, 76]). Moreover, serial visual search abilities at kindergarten resulted predictive of future reading skills at first and second grade of primary school [57•, 77, 78•].

In visual search tasks, in the presence of a highly complex scenario (for example, a letter with more than twenty distractors), AVG players had better performance than non-action video games (NAVG) players [72]. In tasks that do not employ linguistic stimuli, both AVG players and individuals without video games experience but trained with AVG (or driving games) were found to have better skills than control group [79]. Where participants have simply to count the amount of stimuli (dots) on the screen, children with DD resulted mildly impaired, mainly with larger quantities [80, 81]. In these tasks, AVG players are capable of more accurate performance than NAVG ones [71, 82].

However, the attention spotlight is not only oriented in a specific location, but has also to be varied in its size (e.g. [22, 83-93]). The data regarding the useful field of view (UFOV, Fig. 2) task and the effect of AVG seem crucial in developing future video game training for DD. The UFOV 

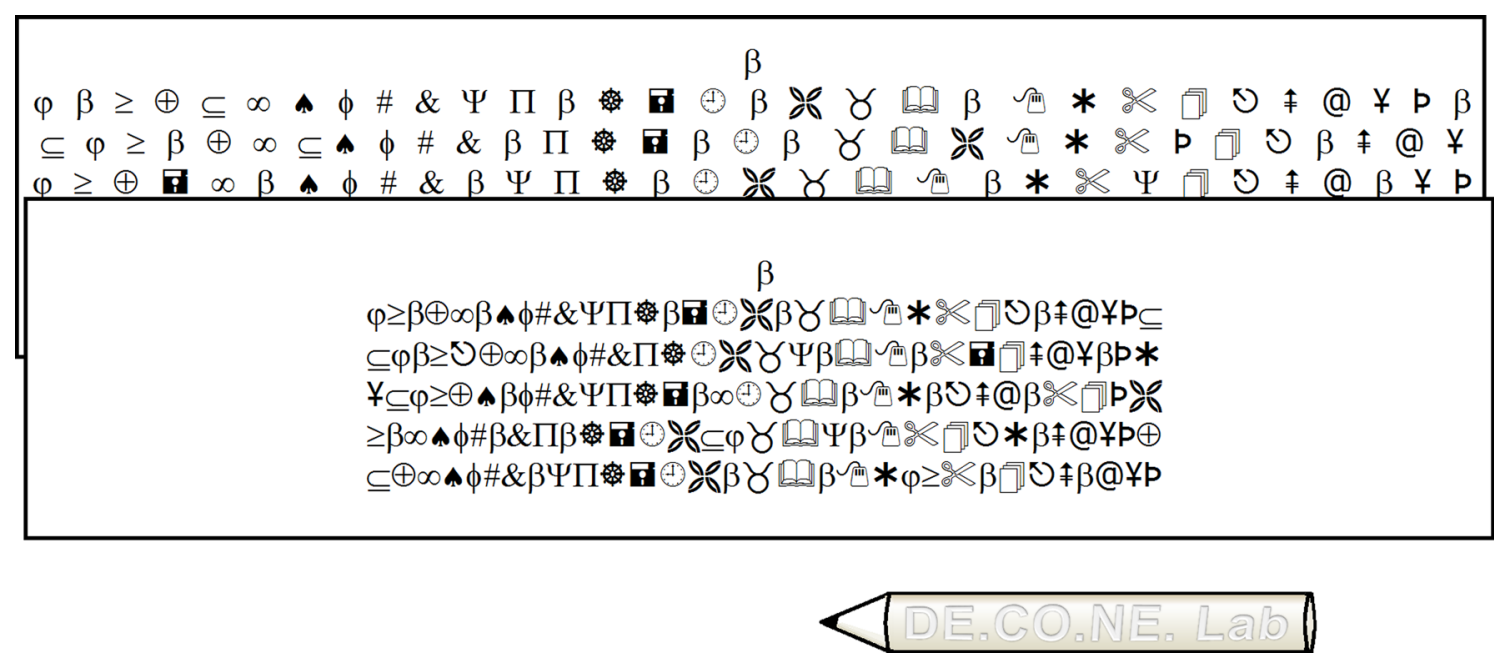

Fig. 1 The two types of serial visual search task (large and small spacing between symbols) employed by Franceschini et al. [78]: children have to cancel all the target symbols, proceeding from left to right and line by line

is a task that evaluates the total area of the visual field within which individuals can obtain useful information without moving their head or eyes [94].

Participants had to detect stimuli that appear at different eccentricities from the centre of the screen. Laasonen et al. [95] testing adults with and without DD or ADHD showed that DD group was poorer than controls, and accuracy threshold of the UFOV resulted correlated with reading abilities. In exactly the same task, AVG players demonstrated far superior performance as compared to NAVG players across all eccentricities [71, 82, 96-98]. Not only AVG players, but also naive participants after training with AVG, showed greater detection abilities in the UFOV ([71]; but see [99]).

Franceschini et al. [100•] showed a direct effect of the AVG training on the spotlight of attention in children with DD. An improvement in the distribution and allocation of visuo-spatial attention was obtained in the Visual Attention Span task (e.g. [20, 101-105]), where participants have to discriminate one of

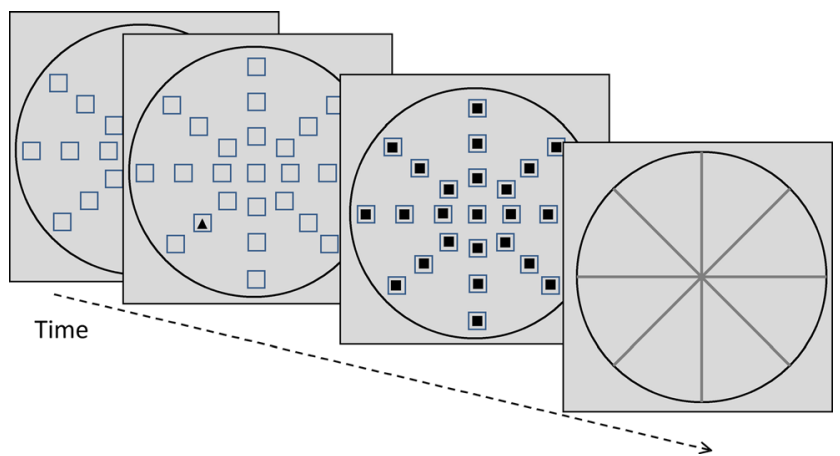

Fig. 2 The useful field of view (UFOV) is a task that evaluates the total area of the visual field within which individuals can obtain useful information without moving their head or eyes [94]. Participants had to detect stimuli that appear at different eccentricities from the centre of the screen (e.g., [71]) six visual stimuli. The training with AVG, compared to a NAVG training, allowed children with DD to improve their abilities in stimulus discrimination both in a condition of distributed and focused attention [100•]. While the focused attention is crucial in shallow languages (e.g. Italian) because the single or the couple of letters are essentially the unit of reading, the distributed attention is necessary to read the trigrams or larger group of letters that are at the basis of reading in opaque languages (e.g. English) [106]. A direct training with AVG appears useful to ameliorate the smaller and weaker attention spotlight [107] of people with DD.

In agreement to the difference found in spatial distribution of attention, word analysis in individuals with DD is slowed because of greater crowding effects $([108,109 \bullet]$, see $[6 \bullet]$ for a recent review), that is, the impaired recognition of a target due to the presence of neighboring objects in the peripheral vision [110]. In the extra-large spacing between letters and words - while reducing crowding - it also improved children (Italian and French) reading accuracy and speed on the fly (without any training) [109•]. Difficulties for both words and symbols indicate that the crowding effect takes place before the process of letter-to-speech-sound mapping [111-113], confirming that this visual deficit is independent from the language transparency.

Across a wide range of eccentricities, AVG players showed significantly reduced crowding as compared to NAVG players. Moreover, people without AVG experience could also reduce their crowding effect with $20 \mathrm{~h}$ of AVG training [114]. Consequently, using AVG training could reduce the crowding in DD.

In individuals with DD, evidence of a deficit in automatic orienting of attention (Posner task, [115]) have been largely demonstrated $([5 \bullet, 25,40,116]$ see $[5 \bullet, 6 \bullet]$ for a review) and causally connected to future reading skills $[27,57 \bullet, 78 \bullet]$. 
The effect of AVG on the exogenous processes of attention is still controversial [71, 72]. AVG players presented no differences in attentional orienting mechanisms, but overall shorter reaction time compared to non-gamers $[72,117]$.

Chisholm and Kingstone [118, 119] showed a marginal effect in saccade latencies (with AVG players faster than NAVG players) during a cued visual search task (but see $[98,118,120])$. West et al. [98] found greater attentional allocation to the cued target location in AVG players compared to NAVG ones.

\section{Visual Temporal Attention in Dyslexia and Action Video Games}

People with DD show also deficit in visual temporal attention [116]. The attentional blink (AB Fig. 3) [121] consists in a two targets among distractors shown in rapid sequence. This task evaluates the time frame necessary for individuals to recognize the first target and also the ability to restart a second attentional analysis in order to discriminate the second one.

Longer recovery times were found in adults and children with DD and with SLI relative to controls in disengaging attention from the first target ([28, 122], see [123] for a review). Individuals with DD and SLI had also poorer performance in recognizing the first stimulus (the target) when a second stimulus (the distractor) appears interrupting the visual processing (i.e. backward masking; [26, 42, 43•, 124-126]. This temporal attention deficit was recently demonstrated to be causally linked to DD by using perceptual learning training [57•].

The literature on AVG effects on the $\mathrm{AB}$ shows that AVG players have faster recovery time than non-AVG players $[71,97]$. A training with AVG can produce significant increases in $\mathrm{AB}$ performance compared with those obtainable with a NAVG training ([97, 127], but see [128]).

Li et al. [129] showed differences between AVG player and non-videogamers in the backward masking. These authors showed that AVG training significantly increases these skills in non-video gamers.

\section{Cross-sensory Attention in Dyslexia and Action Video Games}

Individuals with DD suffer from a deficit of sequences rapid processing, affecting both uni-sensory and cross-sensory perception $[15,130-132]$.

Very few works investigated the effects of AVG on crosssensory processing. Donohue and colleagues [133] found that people with extensive experience playing video games show benefits that impact cross-sensory processing.
Attentional shifting between modalities is impaired in individuals with DD [134•], and Franceschini et al. [100•] demonstrated that only $12 \mathrm{~h}$ of playing AVG improved crosssensory attentional shifting in children with DD.

\section{Auditory Attention in Dyslexia and Action Video Games}

Auditory processing deficits are potentially connected to the phonological deficits and possible causes of DD (see [2, 135] for reviews). Children with SLI and DD [136] show difficulties in perceiving speech when it is presented in background noise [51, 137-139]. Atypical auditory processing characterizes children at risk for DD (e.g. [140]). During infancy, future fluent readers were better in speech processing in comparison to those who became non-fluent readers [141, 142]. Poor readers (with or without SLI) show lower signal to noise ratio in perceiving sounds relative to good readers [139, 143-145]. These disorders in perceptual noise exclusion could be caused by an auditory attentional deficit [25, 27, 89, 146]. Rapid auditory processing in infants and toddlers can predict the future language acquisition skills [147]. Computer games were proved to be efficient auditory temporal processing in language-learning impaired children [148].

Few works have investigated the effects of AVG on auditory processing, probably because of the mainly visual nature of the video games. However, Green et al. [70] demonstrated that AVG players showed better discrimination of pure tones embedded in different levels of white noise, suggesting a possible attentional multi-sensory effect of perceptual noise exclusion mechanism. The ability to sample information over time (i.e. processing speed) was significantly greater in AVG players than in NAVG players.

In the same study, two groups of participants without any experience in video games performed $50 \mathrm{~h}$ of AVG or NAVG training. Only AVG training improved auditory discrimination showing a causal relationship between the more efficient use of auditory stimuli and the AVG play [70].

These results are relevant for a possible AVG training for auditory-phonological processing deficits in individuals with DD. Gori et al. [57•] comparing AVG and NAVG training in children with DD found that pseudo-word repetition accuracy - involving both efficient auditory processing and phonological short-term memory-increased only after an AVG training.

\section{Action Video Game Training in Dyslexia}

Franceschini et al. [100•] demonstrated, for the first time, the positive effects of AVG training on reading abilities in children with DD. These authors measured the phonological 


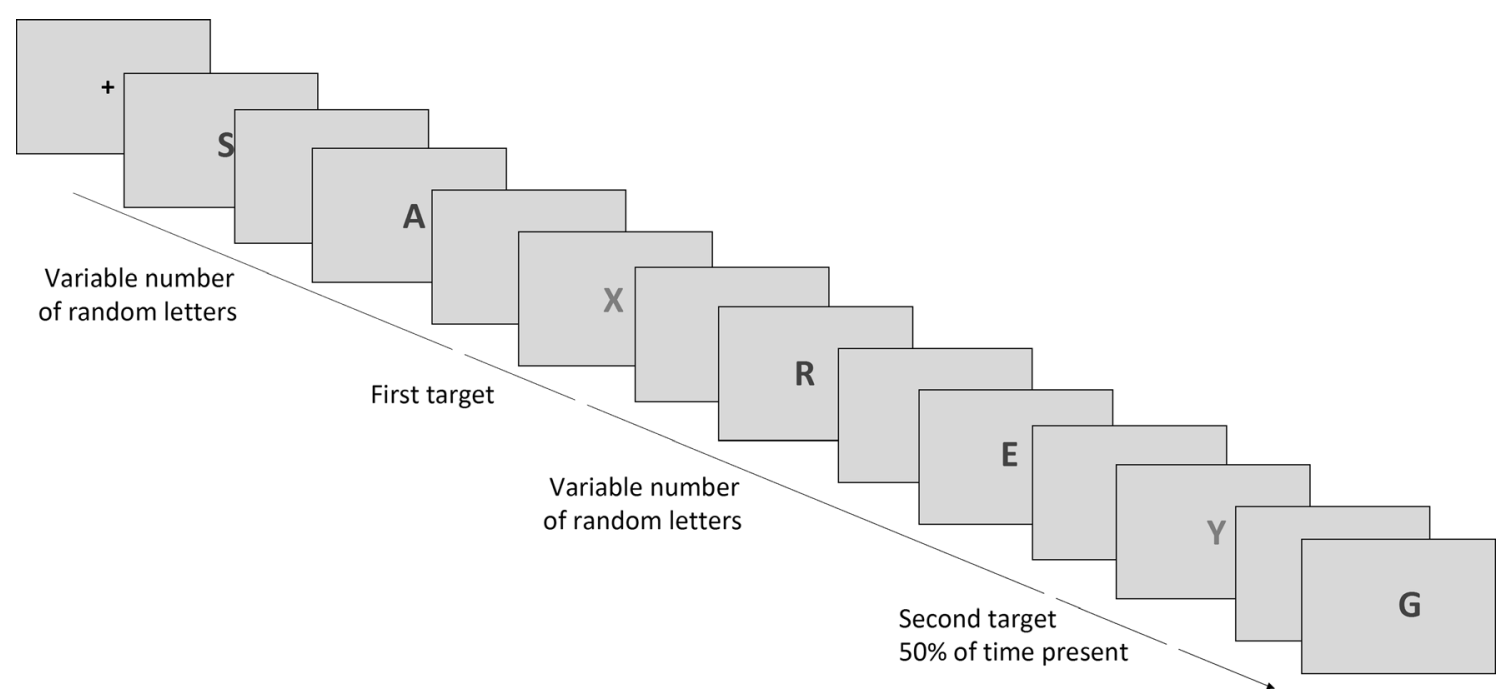

Fig. 3 The attentional blink (AB; Raymond, Shapiro and Arnell, [121]) consists in a two targets (letters in light grey in the example above) among distractors shown in rapid sequence. This task evaluates the time frame

decoding of pseudo-words and word text reading skills in children with DD before and after two video game trainings (AVG or NAVG). After $12 \mathrm{~h}$ of treatment (spaced over 9 days), the AVG training players improves in basic phonological decoding and in lexical recognition measured by the word text reading. Results measured in syllables per seconds showed that children had an improvement higher than what would be expected in a child with after 1 year of spontaneous reading development and bigger or equal than those obtained by the highly demanding traditional DD training [100•]. Individual analysis showed that $80 \%$ of AVG players improved their reading abilities compared to the NAVG group. These results were confirmed by a second study [57•], where a group of children with DD was trained using NAVG before and AVG after in a within-subject design. Whereas the NAVG training led to non-significant results, training with AVG showed large improvements in words and pseudo-words text reading, confirming the importance of using AVG as a possible training in DD. In both studies no drop out was observed.

\section{Neural Substrates of the Action Video Games Training}

Visual system consists of two major pathways: the magnocellular-dorsal (MD) and parvocellular-ventral (PV) streams $[149,150]$. The MD pathway presents a high degree of sensitivity to low contrast, low spatial frequency, high temporal frequency and achromatic visual information. The MD pathway consists of large heavily myelinated neurons with fast conduction velocity and responds maximally to rapid temporal changes [151•]. necessary for individuals to recognize the first target and also the ability to restart a second attentional analysis in order to discriminate the second one

The MD pathway is appointed to the motion perception, both real and illusory [56•,152-158], and it contains the anatomical neural network responsible for the attention orienting $[18,19]$. The MD theory of DD stems from the observation that most reading disabled children are impaired in the specific visual MD pathway (see $[5 \cdot, 6 \bullet, 13,16,17,151 \cdot 159]$ for reviews). Difficulties in discrimination of global motion (i.e. coherent dot motion, [150]; Fig. 4) or specific spatial frequencies grids perception (i.e. frequency doubling illusion; [160]) have been found in individuals with DD (e.g. $[41,56 \bullet, 161])$ and in pre-reading children who will later develop reading difficulties ([49, 51, 57•]; but see [162]).

It has been shown that children with DD have a specific deficit in the MD pathway also compared with younger typically developing children, at the same reading level of DD $[52 \bullet, 53 \bullet]$. Recently, Gori et al. [53•] identified, for the first
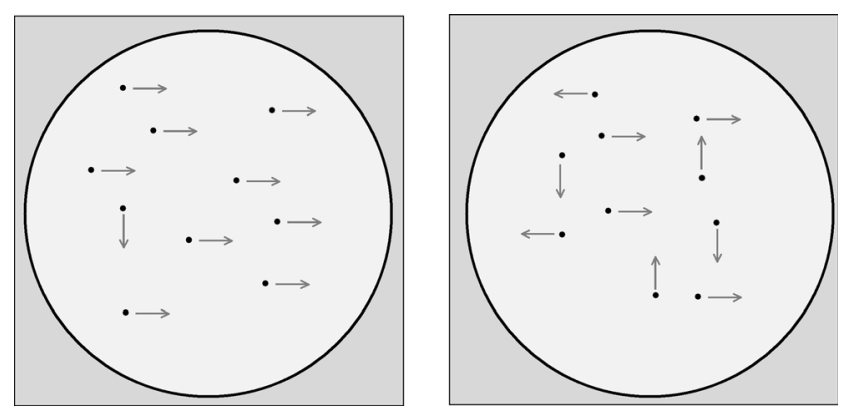

Fig. 4 The coherent dot motion task consists in a circular display where dots are moving. Dots can move coherently with different percentage (in the example above $90 \%$, left; and $40 \%$ right are depicted). Participants were asked to discriminate the direction of dot moving coherently. This task measures the global motion discrimination, and it is the most accepted proxy to evaluate the magnocellular-dorsal pathway functionality 
time, a genetic basis of the MD pathway deficit using two motion illusions (the rotating tilted lines illusion, [154, 163, 164]; and the accordion grating, [165-167]).

In parallel, the performance in the same tasks showed improvements due to the use of AVG (see [168]; but see also [169] for a different result). Crucially, an AVG training has been recently found to improve the ability in real and illusory motion discrimination in children with DD [57•]. AVG players showed better performance in stimulus detection based on spatial frequencies compared to NAVG players [170]. These authors showed that NAVG players improved their stimulus recognition abilities after AVG training.

Alternative explanation of the visual-perceptual difficulties in DD was developed to explain the deficits that children with DD have in detecting gratings when they were embedded in external noise, but not when the same stimuli were presented without noise ([171]; but see [53•]). This alternative hypothesis affirms that DD is associated with deficits in perceptual-noise exclusion, rather than to signal enhancement, supporting the explanation of AVG effects on perception [70]. AVG make individuals more efficient in identifying the signal embedded in noise improving the ability to extract taskrelevant statistics from the environment and to develop better templates for the task at hand [172]. In contrast, perceptual learning is very feature specific (e.g. [173-176]). As well as habitual AVG players or individuals trained with AVG, who present fine-tuned perceptual templates, children with DD, after AVG training, could be more efficient in speech-sound and letter-tospeech-sound learning.

Video game experience could be associated with changes in high-order cognitive functions and with improved connectivity between visual and pre-frontal control areas. These changes may be connected to the improved perceptual learning [177•].

These findings, together with the emerging literature about the involvement of basal ganglia in video game performances [178], extend our comprehension about the possible neural substrates of the video games processing. Briefly, basal ganglia are at the basis of the cortico-cortico connections development and are involved in the acquisition of new behavioural and cognitive schemes [179]. Striatum volume and activation resulted related to DD [180] to phonological processing and SLI [181, 182]. Children with DD and SLI could show deficit in procedural learning [183-185] and also in automatize skills (tested by a Pacman video game, see [186]), suggesting possible deficits in both ventral and dorsal striatum. The volume of basal ganglia resulted strictly related to video game habits $[178,187]$. The cortico-basal ganglia circuit $[188]$ seems to be a good candidate for a neural substrate for both, the changes observed after AVG playing and the documented visualattention deficit showed in DD.

\section{Conclusions}

People with DD show difficulties in several perceptual modalities [50]. These difficulties are connected to the information extraction due to a basic perceptual and/or attentional deficit in the fast information segregation and selection.

In this review, we show that the perceptual and attentional deficits at the basis of DD are influenced by the use of AVG. The findings by Franceschini et al. [100•] and Gori et al. [57•] showed that AVG dramatically improved reading.

The cognitive mechanisms that are specifically trained by the AVG precede the orthographic-to-phonological mapping $[31,61,109 \bullet]$. In particular, the engagement and disengagement mechanisms of visuo-attentional orienting act before the linguistic sub-lexical and lexical conversion routes, making the efficient training of these mechanisms crucial for reading remediation independently from writing systems with varying degrees of consistency in letter-to-speech sound relationships. Thus, an AVG training should be beneficial to individuals with DD regardless the DD subtypes and the deepness of the language.

A recent meta-analysis [68 ${ }^{\bullet}$ shows that although we must be very cautious about the influence of various types of video game on the different cognitive functions, video games led to improved information processing in both quasi-experimental and true experiment studies. Boot et al. [189] also warned about possible placebo effects related to the AVG trainings. However, in both Franceschini et al. [100•] and Gori et al. [57•], the experimental and control groups were equally likely to expect improvements (i.e. children were not aware whether AVG or NAVG had positive effects on reading abilities), and evaluators were blind, making these results not at risk for placebo effects.

As for sport, music, television and video games, playing quantity and quality could make the difference. In the introduction of this review, we reported that the amount of time spent playing video games resulted associated with poorer academic performance [66, 67]. Moreover, He et al. [65] showed that children with DD spend more time than typical readers on computers, instead of studying. Those results could be considered in contradiction with the reading improvement found in children with DD after playing AVG [57•, 100•]. Exactly like knowing that not all the sports are equal in stressing specific abilities, and not all kinds of musical instruments leverage the same mechanisms, only specific video games are useful in increasing reading abilities.

In sum, AVG training is a perfect candidate to be associated to typical trainings (which, however, need to be scientific validated too) in order to reduce DD bad outcomes.

Similar intervention in conjunction was suggested for musical training aiming to improve reading abilities [190-192].

AVG, or video game in general, are one of the most active, absorbing experience from which children can develop visual 
(and probably auditory as well as cross-sensory) perceptual and attentional abilities. The reviewed results show that even few hours of AVG can have profound effects on perceptual and visuo-attentional mechanism directly translating in better reading abilities. Although the results in the literature demonstrated that also at individual level the vast majority of the children showed significant reading improvements, in the worst case scenario, where a given child receives no video game benefit, no negative effects were reported and she/he will have fun.

Finally, since visual attentional and MD dysfunctions can be identified in infancy, our review paves the way for possible early prevention programs that could use AVG training to battle DD even before the diagnosis.

Acknowledgments This work was funded with grants by the CARIPARO Foundation ("Borse di Dottorato CARIPARO 2009" and "Progetti di Eccellenza CARIPARO 2012-2014 rep. no. $1873 / 2012$ " to S. G., L. R.; S.F. and A. F.) by the University of Padua ("Young Researcher 2014" to L.R.; Progetto di Ateneo 2011; 2014 to A.F. and S. F.).

\section{Compliance with Ethics Guideline}

Conflict of Interest Sandro Franceschini, Sara Bertoni, Luca Ronconi, Massimo Molteni, Simone Gori, and Andrea Facoetti declare that they have no conflict of interest.

Human and Animal Rights and Informed Consent This article does not contain any studies with human or animal subjects performed by any of the authors.

\section{References}

Papers of particular interest, published recently, have been highlighted as:

- Of importance

1. Gabrieli JD. Dyslexia: a new synergy between education and cognitive neuroscience. Science. 2009;325(5938):280-3.

2. Tallal P. Improving language and literacy is a matter of time. Nat Rev Neurosci. 2004;5(9):721-8.

3. Nicolson RI, Fawcett AJ. Procedural learning difficulties: reuniting the developmental disorders? Trends Neurosci. 2007;30(4):13541.

4. Stein J. Dyslexia: the role of vision and visual attention. Curr Dev Disord Rep. 2014;1(4):267-80. A very comprehensive review regarding the role of the $M-D$ pathway in the reading, the factors underlying M-D pathway vulnerability and possible treatments.

5. Gori S, Facoetti A. Perceptual learning as a possible new approach for remediation and prevention of developmental dyslexia. Vis Res. 2014;99:78-87. A very comprehensive review regarding the role of the M-D pathway and attention in the reading, the factors underlying M-D pathway vulnerability and possible perceptual learning treatments.
6. Gori S, Facoetti A. How the visual aspects can be crucial in reading acquisition: the intriguing case of crowding and developmental dyslexia. J Vis. 2015;15(1):15.1.8. The first and, at the present time, the only, review article regarding the role of crowding on reading and possible crowding treatments in DD.

7. Peterson RL, Pennington BF. Developmental dyslexia. Lancet. 2012;379(9830):1997-2007.

8. Blomert L. The neural signature of orthographic-phonological binding in successful and failing reading development. Neuroimage. 2011;57(3):695-703.

9. Perfetti CA. Reading ability. New York: Oxford University Press; 1985.

10. Breznitz Z, Shaul S, Horowitz-Kraus T, Sela I, Nevat M, Karni A. Enhanced reading by training with imposed time constraint in typical and dyslexic adults. Nat Commun. 2013;4:1486. This study shows that adults with DD can experience long-lasting improvements in reading speed and comprehension when they are trained to read with increasingly demanding imposed time constraint (letter-by-letter masking).

11. Blau V, van Atteveldt N, Ekkebus M, Goebel R, Blomert L. Reduced neural integration of letters and speech sounds links phonological and reading deficits in adult dyslexia. Curr Biol. 2009;24(6):503-8.

12. Boets B, Op de Beeck HP, Vandermosten M, Scott SK, Gillebert $\mathrm{CR}$, Mantini D, et al. Intact but less accessible phonetic representations in adults with dyslexia. Science. 2013;342(6163):1251-4. These authors employed functional neuroimaging to show that the neural substrates of phonological representation are intact in individuals with DD, but the access to these representations are hampered by dysfunctional connections between frontal and temporal language areas.

13. Stein J, Walsh V. To see but not to read; the magnocellular theory of dyslexia. Trends Neurosci. 1997;20(4):147-52.

14. Vidyasagar TR. A neuronal model of attentional spotlight: parietal guiding the temporal. Brain Res Brain Res Rev. 1999;30(1):66-76.

15. Hari R, Renvall H. Impaired processing of rapid stimulus sequences in dyslexia. Trends Cogn Sci. 2001;5(12):525-32.

16. Boden C, Giaschi D. M-stream deficits and reading-related visual processes in developmental dyslexia. Psychol Bull. 2007;133(2): 346-66.

17. Vidyasagar TR, Pammer K. Dyslexia: a deficit in visuo-spatial attention, not in phonological processing. Trends Cogn Sci. 2010;14(2):57-63.

18. Corbetta M, Shulman GL. Control of goal-directed and stimulus-driven attention in the brain. Nat Rev Neurosci. 2002;3(3):201-15.

19. Dosenbach NU, Fair DA, Cohen AL, Schlaggar BL, Petersen SE. A dual networks architecture of top-down control. Trends Cogn Sci. 2008;12(3):99-105.

20. Bosse ML, Tainturier MJ, Valdois S. Developmental dyslexia: the visual attention span deficit hypothesis. Cognition. 2007;104(2): 198-230.

21. Brannan JR, Williams MC. Allocation of visual attention in good and poor readers. Percept Psychophys. 1987;41(1):23-8.

22. Facoetti A, Paganoni P, Turatto M, Marzola V, Mascetti GG. Visual-spatial attention in developmental dyslexia. Cortex. 2000;36(1):109-23.

23. Facoetti A, Molteni M. The gradient of visual attention in developmental dyslexia. Neuropsychologia. 2001;39(4):352-7.

24. Facoetti A, Turatto M, Lorusso ML, Mascetti GG. Orienting of visual attention in dyslexia: evidence for asymmetric hemispheric control of attention. Exp Brain Res. 2001;138(1):46-53.

25. Facoetti A, Lorusso ML, Cattaneo C, Galli R, Molteni M. Visual and auditory attentional capture are both sluggish in children with developmental dyslexia. Acta Neurobiol Exp. 2005;65(1):61-72. 
26. Facoetti A, Ruffino M, Peru A, Paganoni P, Chelazzi L. Sluggish engagement and disengagement of non-spatial attention in dyslexic children. Cortex. 2008;44(9):1221-33.

27. Facoetti A, Corradi N, Ruffino M, Gori S, Zorzi M. Visual spatial attention and speech segmentation are both impaired in preschoolers at familial risk for developmental dyslexia. Dyslexia. 2010;16(3):226-39.

28. Hari R, Renvall H, Tanskanen T. Left minineglect in dyslexic adults. Brain. 2001;124(Pt7):1373-80.

29. Vidyasagar TR, Pammer K. Impaired visual search in dyslexia relates to the role of the magnocellular pathway in attention. Neuroreport. 1999;10(6):1283-7.

30. Williams M, Brannan J, Lartigue E. Visual search in good and poor readers. Clin Vision Sci. 1987;1:367-71.

31. Valdois S, Gérard C, Vanault P, Dugas M. Peripheral developmental dyslexia: a visual attentional account? Cognit Neuropsychol. 1995;12(1):31-67.

32. Iles J, Walsh V, Richardson A. Visual search performance in dyslexia. Dyslexia. 2000;6(3):163-77.

33. Hari R, Valta M, Uutela K. Prolonged attentional dwell time in dyslexic adults. Neurosci Lett. 1999;271(3):202-4.

34. Buchholz J, Aimola Davies A. Attentional blink deficits observed in dyslexia depend on task demands. Vis Res. 2007;47(10):1292-302.

35. Lobier MA, Peyrin C, Pichat C, Le Bas JF, Valdois S. Visual processing of multiple elements in the dyslexic brain: evidence for a superior parietal dysfunction. Front Hum Neurosci. 2014;8: 479. This study reports a comparison of visual attention span abilities between individuals with DD and normal readers and showed the underlying brain basis.

36. Cestnick L, Coltheart M. The relationship between languageprocessing and visual-processing deficits in developmental dyslexia. Cognition. 1999;71(3):231-55.

37. Jones MW, Branigan HP, Kelly ML. Visual deficits in developmental dyslexia: relationships between non-linguistic visual tasks and their contribution to components of reading. Dyslexia. 2008;14(2):95-115.

38. Roach NW, Hogben JH. Impaired filtering of behaviourally irrelevant visual information in dyslexia. Brain. 2007;130:771-85.

39. Facoetti A, Zorzi M, Cestnick L, Lorusso ML, Molteni M, Paganoni $\mathrm{P}$, et al. The relationship between visuo-spatial attention and nonword reading in developmental dyslexia. Cogn Neuropsychol. 2006;23(6):841-55.

40. Facoetti A, Trussardi AN, Ruffino M, Lorusso ML, Cattaneo C, Galli R, et al. Multisensory spatial attention deficits are predictive of phonological decoding skills in developmental dyslexia. J Cogn Neurosci. 2010;22(5):1011-25.

41. Buchholz J, McKone E. Adults with dyslexia show deficits on spatial frequency doubling and visual attention tasks. Dyslexia. 2004;10(1):24-43

42. Ruffino M, Trussardi AN, Gori S, Finzi A, Giovagnoli S, Menghini D, et al. Attentional engagement deficits in dyslexic children. Neuropsychologia. 2010;48(13):3793-801.

43. Ruffino M, Gori S, Boccardi D, Molteni M, Facoetti A. Spatial and temporal attention in developmental dyslexia. Front Hum Neurosci. 2014;8:331. This study reports the first results about spatial and temporal attention deficits in the same sample of children with DD.

44. Zhao J, Qian Y, Bi HY, Coltheart M. The visual magnocellulardorsal dysfunction in Chinese children with developmental dyslexia impedes Chinese character recognition. Sci Rep. 2014;4:7068

45. Liu D, Chen X, Chung KKH. Performance in a visual search task uniquely predicts reading abilities in third-grade Hong Kong Chinese children. Sci Stud Read. 2015;19(4):307-24.
46. Galaburda A, Livingstone M. Evidence for a magnocellular defect in developmental dyslexia. Ann N Y Acad Sci. 1993;682:70-82.

47. Stein JF, Talcott JB. Impaired neuronal timing in developmental dyslexia- the magnocellular hypothesis. Dyslexia. 1999;5:59-78.

48. Kevan A, Pammer K. Visual processing deficits in preliterate children at familial risk for dyslexia. Vis Res. 2008;48(28):2835-9.

49. Kevan A, Pammer K. Predicting early reading skills from prereading measures of dorsal stream functioning. Neuropsychologia. 2009;47(14):3174-81.

50. Menghini D, Finzi A, Benassi M, Bolzani R, Facoetti A, Giovagnoli $\mathrm{S}$, et al. Different underlying neurocognitive deficits in developmental dyslexia: a comparative study. Neuropsychologia. 2010;48(4): 863-72.

51. Boets B, Vandermosten M, Cornelissen P, Wouters J, Ghesquière P. Coherent motion sensitivity and reading development in the transition from prereading to reading stage. Child Dev. 2011;82(3):854-69.

52. Gori S, Cecchini P, Bigoni A, Molteni M, Facoetti A. Magnocellulardorsal pathway and sub-lexical route in developmental dyslexia. Front Hum Neurosci. 2014;8. This study showed for the first time that children with DD presented impaired magnocellular pathway also in comparison with reading level controls.

53. Gori S, Mascheretti S, Giora E, Ronconi L, Ruffino M, Quadrelli $\mathrm{E}$, et al. The DCDC2 intron 2 deletion impairs illusory motion perception unveiling the selective role of magnocellular-dorsal stream in reading (Dis)ability. Cereb Cortex. 2015;25(6):168595. This study showed, for the first time, that children with DD presented impaired dorsal pathway also in comparison with reading level controls and with stimuli that are not related with signal to noise extraction. This study also found the first genetic association between the M-D pathway and specific genetic variance.

54. Livingstone MS, Rosen GD, Drislane FW, Galaburda AM. Physiological and anatomical evidence for a magnocellular defect in developmental dyslexia. Proc Natl Acad Sci U S A. 1991;15(18):7943-7.

55. Giraldo-Chica M, Hegarty JP 2nd, Schneider KA. Morphological differences in the lateral geniculate nucleus associated with dyslexia. Neuroimage Clin. 2015;830-836. This study is the first in vivo study showed that individuals with DD presented smaller LGN volume, supporting the M-D pathway deficit theory in DD.

56. Gori S, Stubbs DA. Motion illusions as a psychophysical tool to investigate the visual system. In: Geremek A, Greenlee MW, Magnussen S, editors. Perception beyond Gestalt: progress in vision research New York. U.S.A.: Psychology Press; 2014. p. 12843. This chapter is a very comprehensive review about motion illusion and how they cen be used as a tool to understand our visual system.

57. Gori S, Seitz AR, Ronconi L, Franceschini S, Facoetti A. Multiple causal links between magnocellular-dorsal pathway deficit and developmental dyslexia. Cereb Cortex. doi:10.1093/cercor/ bhv206. This study demonstrate for the first time a clear causal role of the M-D pathway deficit in reading disorders. The authors showed in $\mathbf{4}$ experiments that the M-D deficit is present also if individuals with DD are compared with reading level controls, that children with an M-D deficit at prereading stage will become poor readers during the first year of primary school and that two trainings able to improve M-D functionality results in dramatically reading improvements without any phonological or orthographic training.

58. Dehaene S, Cohen L, Morais J, Kolinsky R. Illiterate to literate: behavioural and cerebral changes induced by reading acquisition. Nat Rev Neurosci. 2015;16(4):234-44.

59. Roelfsema PR. Elemental operations in vision. Trends Cogn Sci. 2005;9(5):226-33. 
60. Roelfsema PR, van Ooyen A, Watanabe T. Perceptual learning rules based on reinforcers and attention. Trends Cogn Sci. 2010;14(2):64-71.

61. McCandliss BD, Cohen L, Dehaene S. The visual word form area: expertise for reading in the fusiform gyrus. Trends Cogn Sci. 2003;7(7):293-9.

62. Carreiras M, Armstrong BC, Perea M, Frost R. The what, when, where, and how of visual word recognition. Trends Cogn Sci. 2014;18(2):90-8.

63. McArthur G, Eve PM, Jones K, Banales E, Kohnen S, Anandakumar T, et al. Phonics training for English-speaking poor readers. Cochrane Database Syst Rev. 2012;12: CD009115.

64. Dehaene S, Pegado F, Braga LW, Ventura P, Nunes FG, Jobert A, et al. How learning to read changes the cortical networks for vision and language. Science. 2010;330(6009):1359-64.

65. He Z, Shao S, Zhou J, Ke J, Kong R, Guo S, et al. Does long time spending on the electronic devices affect the reading abilities? a cross-sectional study among Chinese school-aged children. Res Dev Disabil. 2014;35(12):3645-54.

66. Hastings EC, Karas TL, Winsler A, Way E, Madigan A, Tyler S. Young children's video/computer game use: relations with school performance and behavior. Issues Ment Health Nurs. 2009;30(10): 638-49.

67. Jackson LA, Fitzgerald HE, Zhao Y, Kolenic A, von Eye A, Harold R. Information technology (IT) use and children's psychological well-being. Cyberpsychol Behav. 2008;11(6):755-7.

68. Powers KL, Brooks PJ, Aldrich NJ, Palladino MA, Alfieri L. Effects of video-game play on information processing: a metaanalytic investigation. Psychon Bull Rev. 2013;20(6):1055-79. A recent meta-analysis on the effect of different types of video game on various information-processing skills, such as auditory processing, executive functions, motor skills, spatial imagery and visual processing.

69. Cardoso-Leite P, Bavelier D. Video game play, attention, and learning: how to shape the development of attention and influence learning? Curr Opin Neurol. 2014;27(2):185-91.

70. Green CS, Li R, Bavelier D. Perceptual learning during action video game playing. Top Cogn Sci. 2010;2(2):202-16.

71. Green CS, Bavelier D. Action video game modifies visual selective attention. Nature. 2003;423(6939):534-7.

72. Hubert-Wallander B, Green CS, Sugarman M, Bavelier D. Changes in search rate but not in the dynamics of exogenous attention in action videogame players. Atten Percept Psycophys. 2011;73:2399-412.

73. Treisman A. Features and objects: the fourteenth Bartlett memorial lecture. Q J Exp Psychol A. 1988;40(2):201-37.

74. Posner MI, Petersen SE. Attentional system of the human brain. Annu Rev Neurosci. 1990;13:25-42.

75. Casco C, Tressoldi PE, Dellantonio A. Visual selective attention and reading efficiency are related in children. Cortex. 1998;34: 531-46.

76. Sireteanu R, Goebel C, Goertz R, Werner I, Nalewajko M, Thiel A. Impaired serial visual search in children with developmental dyslexia. Ann N Y Acad Sci. 2008;1145:199-211.

77. Ferretti G, Mazzotti S, Brizzolara D. Visual scanning and reading ability in normal and dyslexic children. Behav Neurol. 2008;19: 87-92.

78. Franceschini S, Gori S, Ruffino M, Pedrolli K, Facoetti A. A causal link between visual spatial attention and reading acquisition. Curr Biol. 2012;22(9):814-9. In a longitudinal perspective study the authors showed, for the first time, a clear causal role of the visuo-attentional abilities of children at kindergarten on reading skills acquisition during the first and second year of primary school.
79. Wu S, Spence I. Playing shooter and driving videogames improves top-down guidance in visual search. Atten Percept Psychophys. 2013;75(4):673-86.

80. Eden GF, Stein JF, Wood HM, Wood FB. Temporal and spatial processing in reading disabled and normal children. Cortex. 1995;31(3):451-68.

81. Wilson AJ, Andrewes SG, Struthers H, Rowe VM, Bogdanovic R, Waldie KE. Dyscalculia and dyslexia in adults: cognitive bases of comorbidity. Learn Individ Differ. 2015;37:118-32.

82. Green CS, Bavelier D. Enumeration versus multiple object tracking: the case of action video game players. Cognition. 2006;101: 217-45.

83. Castiello U, Umiltà C. Size of the attentional focus and efficiency of processing. Acta Psychol. 1990;73(3):195-209.

84. Müller NG, Bartelt OA, Donner TH, Villringer A, Brandt SA. A physiological correlate of the "Zoom Lens" of visual attention. J Neurosci. 2003;23(9):3561-5.

85. Fu S, Greenwood PM, Parasuraman R. Brain mechanisms of involuntary visuospatial attention: an event-related potential study. Hum Brain Mapp. 2005;25(4):378-90.

86. Turatto M, Benso F, Facoetti A, Galfano G, Mascetti GG, Umiltà C. Automatic and voluntary focusing of attention. Percept Psychophys. 2000;62(5):935-52.

87. Facoetti A, Molteni M. Is attentional focusing an inhibitory process at distractor location? Brain Res Cogn Brain Res. 2000;10(12): $185-8$.

88. Facoetti A, Molteni M. The gradient of visual attention in developmental dyslexia. Neuropsychologia. 2001;39(4):352-7.

89. Facoetti A, Lorusso ML, Paganoni P, Cattaneo C, Galli R, Mascetti GG. The time course of attentional focusing in dyslexic and normally reading children. Brain Cogn. 2003;53(2):181-4.

90. Ronconi L, Gori S, Ruffino M, Franceschini S, Urbani B, Molteni $\mathrm{M}$, et al. Decreased coherent motion discrimination in autism spectrum disorder: the role of attentional zoom-out deficit. PLoS One. 2012;7:e49019.

91. Ronconi L, Gori S, Ruffino M, Molteni M, Facoetti A. Zoom-out attentional impairment in children with autism spectrum disorder. Cortex. 2013;49(4):1025-33.

92. Ronconi L, Basso D, Gori S, Facoetti A. TMS on right frontal eye fields induces an inflexible focus of attention. Cereb Cortex. 2014;24(2):396-402.

93. Ronconi L, Franchin L, Valenza E, Gori S, Facoetti A. The attentional 'zoom-lens' in 8-month-old infants. Dev Sci. 2015. doi:10. 1111/desc. 12288.

94. Ball KK, Beard BL, Roenker DL, Miller RL, Griggs DS. Age and visual search: expanding the useful field of view. J Opt Soc Am A. 1988;5(12):2210-9.

95. Laasonen M, Salomaa J, Cousineau D, Leppämaki S, Tani P, Hokkanen L, et al. Project DyAdd: visual attention in adult dyslexia and ADHD. Brain Cogn. 2012;80(3):311-27.

96. Feng J, Spence I, Pratt J. Playing an action video game reduces gender differences in spatial cognition. Psychol Sci. 2007;18(10): $850-5$.

97. Dye MW, Bavelier D. Differential development of visual attention skills in school-age children. Vision Res. 2010;50(4):452-9.

98. West GL, Stevens SA, Pun C, Pratt J. Visuospatial experience modulates attentional capture: evidence from action video game players. J Vis. 2008;8(16):13.1-9.

99. Murphy K, Spencer A. Playing video games does not make for better visual attention skills. J Art Support Null Hypothesis. 2009;6:1-20.

100. Franceschini S, Gori S, Ruffino M, Viola S, Molteni M, Facoetti A. Action video games make dyslexic children read better. Curr Biol. 2013;23(6):462-6. These study demonstrated a direct effect of AVG on perceptual and visuo-attentional mechanisms in children and showed for the first time how these 
improvement directly translate in a dramatic increase of reading abilities in children with DD, without any phonological or orthographical training.

101. Lallier M, Donnadieu S, Valdois S. Visual attentional blink in dyslexic children: parameterizing the deficit. Vision Res. 2010;50(18):1855-61.

102. Peyrin C, Démonet JF, N'Guyen-Morel MA, Le Bas JF, Valdois S. Superior parietal lobule dysfunction in a homogeneous group of dyslexic children with a visual attention span disorder. Brain Lang. 2011;118(3):128-38.

103. Lobier M, Zoubrinetzky R, Valdois S. The visual attention span deficit in dyslexia is visual and not verbal. Cortex. 2012;48(6): 768-73.

104. Reilhac C, Peyrin C, Démonet JF, Valdois S. Role of the superior parietal lobules in letter-identity processing within strings: FMRI evidence from skilled and dyslexic readers. Neuropsychologia. 2013;51(4):601-12.

105. Lobier MA, Peyrin C, Pichat C, Le Bas JF, Valdois S. Visual processing of multiple elements in the dyslexic brain: evidence for a superior parietal dysfunction. Front Hum Neurosci. 2014;8: 479 .

106. Gori S, Facoetti A. Is the language transparency really that relevant for the outcome of the action video games training? Curr Biol 2013; 23, http://www.cell.com/current-biology/abstract/S09609822(13)00258-3\#Comments. Comment on the Dispatch by Bavelier et al. Curr Biol. 2013;23:R282-3.

107. Moores E, Tsouknida E, Romani C. Adults with dyslexia can use cues to orient and constrain attention but have a smaller and weaker attention spotlight. Vision Res. 2015;111((Pt A)):55-65.

108. Martelli M, Di Filippo G, Spinelli D, Zoccolotti P. Crowding, reading, and developmental dyslexia. J Vis. 2009;9(4):14.1-18.

109. Zorzi M, Barbiero C, Facoetti A, Lonciari I, Carrozzi M, Montico $\mathrm{M}$, et al. Extra spacing letter improves reading in dyslexia. Proc Natl Acad Sci U S A. 2012;109(28):11455-9. In this study was showed how children with DD present greater crowding effect during reading in comparison to reding level controls, and how simply enlarge the space between words and letters is able to solve the problem on the fly.

110. Bouma $\mathrm{H}$. Interaction effects in parafoveal letter recognition. Nature. 1970;226(5241):177-8.

111. Spinelli D, De Luca M, Judica A, Zoccolotti P. Crowding effects on word identification in developmental dyslexia. Cortex. 2002;38(2):179-200

112. Moores E, Cassim R, Talcott JB. Adults with dyslexia exhibit large effects of crowding, increased dependence on cues, and detrimental effects of distractors in visual search tasks. Neuropsychologia. 2011;49(14):3881-90.

113. Cassim R, Talcott JB, Moores E. Adults with dyslexia demonstrate large effects of crowding and detrimental effects of distractors in a visual tilt discrimination task. PLoS One. 2014;9(9):e106191.

114. Green CS, Bavelier D. Action-video-game experience alters the spatial resolution of vision. Psychol Sci. 2007;18(1):88-94.

115. Posner MI. Orienting of attention. Q J Exp Psychol. 1980;32(1): 3-25.

116. Facoetti A. Spatial attention disorders in developmental dyslexia: towards the prevention of reading acquisition deficits. In: Stein J, Kapoula Z, editors. Visual aspect of dyslexia. Oxford: Oxford University Press; 2012. p. 123-36.

117. Castel AD, Pratt J, Drummond E. The effects of action video game experience on the time course of inhibition of return and the efficiency of visual search. Acta Psychol. 2005;119(2):217-30.

118. Chisholm JD, Kingstone A. Improved top-down control reduces oculomotor capture: the case of action video game players. Atten Percept Psychophys. 2012;74(2):257-62.

119. Chisholm JD, Kingstone A. Action video games and improved attentional control: disentangling selection- and response-based processes. Psychon Bull Rev. 2015. doi:10.3758/s13423-0150818-3.

120. Chisholm JD, Kingstone A. Action video game players' visual search advantage extends to biologically relevant stimuli. Acta Psychol. 2015;159:93-9.

121. Raymond JE, Shapiro KL, Arnell KM. Temporary suppression of visual processing in an RSVP task: an attentional blink? J Exp Psychol Hum Percept Perform. 1992;18(3):849-60.

122. Lum JA, Conti-Ramsden G, Lindell AK. The attentional blink reveals sluggish attentional shifting in adolescents with specific language impairment. Brain Cogn. 2007;63(3):287-95.

123. Badcock NA, Kidd JC. Temporal variability predicts the magnitude of between-group attentional blink differences in developmental dyslexia: a meta-analysis. PeerJ. 2015;22(3):e746.

124. Di Lollo V, Hanson D, McIntyre JS. Initial stages of visual information processing in dyslexia. J Exp Psychol Hum Percept Perform. 1983;9(6):923-35.

125. Visser TA, Boden C, Giaschi DE. Children with dyslexia: evidence for visual attention deficits in perception of rapid sequences of objects. Vision Res. 2004;44(21):2521-35.

126. Dispaldro M, Leonard LB, Corradi N, Ruffino M, Bronte T, Facoetti A. Visual attentional engagement deficits in children with specific language impairment and their role in real-time language processing. Cortex. 2013;49(8):2126-39.

127. Oei AC, Patterson MD. Enhancing cognition with video games: a multiple game training study. PLoS One. 2013;8(3):e58546.

128. Boot WR, Kramer AF, Simons DJ, Fabiani M, Gratton G. The effects of video game playing on attention, memory, and executive control. Acta Psychol. 2008;129(3):387-98.

129. Li R, Polat U, Scalzo F, Bavelier D. Reducing backward masking through action game training. J Vis. 2010;10(14).

130. Grant AC, Zangaladze A, Thiagarajah MC, Sathian K. Tactile perception in developmental dyslexia: a psychophysical study using gratings. Neuropsychologia. 1999;37(10):1201-11.

131. Virsu V, Lahti-Nuuttila P, Laasonen M. Crossmodal temporal processing acuity impairment aggravates with age in developmental dyslexia. Neurosci Lett. 2003;336(3):151-4.

132. Laasonen M, Tomma-Halme J, Lahti-Nuuttila P, Service E, Virsu $\mathrm{V}$. Rate of information segregation in developmentally dyslexic children. Brain Lang. 2000;75(1):66-81.

133. Donohue SE, Woldorff MG, Mitroff SR. Video game players show more precise multisensory temporal processing abilities. Atten Percept Psychophys. 2010;72(4):1120-9.

134. Harrar V, Tammam J, Pérez-Bellido A, Pitt A, Stein J, Spence C. Multisensory integration and attention in developmental dyslexia. Curr Biol. 2014;24(5):531-5. In this study it is showed how distribution of attentional resources is different in adults with DD compared to normal readers, and sluggish attentional shifting is evidenced in tasks were attention is shifted from visual to auditory modality.

135. Goswami U. Sensory theories of developmental dyslexia: three challenges for research. Nat Rev Neurosci. 2015;16(1):43-54.

136. Torppa M, Poikkeus AM, Laakso ML, Eklund K, Lyytinen H. Predicting delayed letter knowledge development and its relation to grade 1 reading achievement among children with and without familial risk for dyslexia. Dev Psychol. 2006;42(6):1128-42.

137. Ziegler JC, Goswami U. Reading acquisition, developmental dyslexia, and skilled reading across languages: a psycholinguistic grain size theory. Psychol Bull. 2005;131(1):3-29.

138. Geiger G, Cattaneo C, Galli R, Pozzoli U, Lorusso ML, Facoetti $\mathrm{A}$, et al. Wide and diffuse perceptual modes characterize dyslexics in vision and audition. Perception. 2008;37(11):1745-64.

139. Boets B, Ghesquière P, van Wieringen A, Wouters J. Speech perception in preschoolers at family risk for dyslexia: relations with low-level auditory processing and phonological ability. Brain Lang. 2007;101(1):19-30. 
140. Raschle NM, Chang M, Gaab N. Structural brain alterations associated with dyslexia predate reading onset. Neuroimage. 2011;57(3):742-9.

141. Guttorm TK, Leppänen PH, Hämäläinen JA, Eklund KM, Lyytinen HJ. Newborn event-related potentials predict poorer pre-reading skills in children at risk for dyslexia. J Learn Disabil. 2010;43(5):391-401.

142. van Zuijen TL, Plakas A, Maassen BA, Maurits NM, van der Leij A. Infant ERPs separate children at risk of dyslexia who become good readers from those who become poor readers. Dev Sci. 2013;16(4):554-63.

143. Hartley DE, Moore DR. Auditory processing efficiency deficits in children with developmental language impairments. J Acoust Soc Am. 2002;112(6):2962-6.

144. Chandrasekaran B, Hornickel J, Skoe E, Nicol T, Kraus N. Context-dependent encoding in the human auditory brainstem relates to hearing speech in noise: implications for developmental dyslexia. Neuron. 2009;64(3):311-9.

145. Boets B, Wouters J, van Wieringen A, De Smedt B, Ghesquière P. Modelling relations between sensory processing, speech perception, orthographic and phonological ability, and literacy achievement. Brain Lang. 2008;106(1):29-40.

146. Renvall H, Hari R. Auditory cortical responses to speech-like stimuli in dyslexic adults. J Cogn Neurosci. 2002;14(5):757-68.

147. Benasich AA, Tallal P. Infant discrimination of rapid auditory cues predicts later language impairment. Behav Brain Res. 2002;136(1):31-49.

148. Tallal P, Miller SL, Bedi G, Byma G, Wang X, Nagarajan SS, et al. Language comprehension in language-learning impaired children improved with acoustically modified speech. Science. 1996;271(5245):81-4

149. Goodale MA, Milner AD. Separate visual pathways for perception and action. Trends Neurosci. 1992;15(1):20-5.

150. Merigan $\mathrm{WH}$, Maunsell JH. How parallel are the primate visual pathways? Annu Rev Neurosci. 1993;16:369-402.

151. Pammer K. Temporal sampling in vision and the implications for dyslexia. Front Hum Neurosci. 2014;7:933. In this article it is explained the role of visual code inside the temporal sampling framework theory.

152. Livingstone MS, Hubel DH. Psychophysical evidence for separate channels for the perception of form, color, movement, and depth. J Neurosci. 1987;7(11):3416-68.

153. Morrone MC, Tosetti M, Montanaro D, Fiorentini A, Cioni G, Burr DC. A cortical area that responds specifically to optic flow, revealed by fMRI. Nat Neurosci. 2000;3:1322-8.

154. Gori S, Hamburger K. A new motion illusion: the Rotating-TiltedLines illusion. Perception. 2006;35:853-85.

155. Gori S, Agrillo C, Dadda M, Bisazza A. Do fish perceive illusory motion? Sci Rep. 2014;4:6443.

156. Gori S, Giora E, Stubbs DA. Perceptual compromise between apparent and veridical motion indices: the unchained-dots illusion. Perception. 2010;39:863-6.

157. Agrillo C, Gori S, Beran MJ. Do rhesus monkeys (Macaca mulatta) perceive illusory motion? Anim Cogn. 2015;18(4):895910.

158. Ruzzoli M, Gori S, Pavan A, Pirulli C, Marzi CA, Miniussi C. The neural basis of the Enigma illusion: a transcranial magnetic stimulation study. Neuropsychologia. 2011;49(13):3648-55.

159. Vidyasagar TR. Reading into neuronal oscillations in the visual system: implications for developmental dyslexia. Front Hum Neurosci. 2013;7:811.

160. Kelly D. Frequency doubling in visual responses. JOSA. 1966; 56(11):1628-32.

161. Pammer K, Wheatley C. Isolating the M (y)-cell response in dyslexia using the spatial frequency doubling illusion. Vision Res. 2001;41(16):2139-47.
162. Olulade OA, Napoliello EM, Eden GF. Abnormal visual motion processing is not a cause of dyslexia. Neuron. 2013;79(1):180-90.

163. Gori S, Yazdanbakhsh A. The riddle of the rotating-tilted-lines illusion. Perception. 2008;37(4):631-5.

164. Yazdanbakhsh A, Gori S. A new psychophysical estimation of the receptive field size. Neurosci Lett. 2008;438(2):246-51.

165. Gori S, Giora E, Yazdanbakhsh A, Mingolla E. A new motion illusion based on competition between two kinds of motion processing units: the accordion grating. Neural Netw. 2011;24(10): 1082-92.

166. Gori S, Giora E, Yazdanbakhsh A, Mingolla E. The novelty of the accordion-grating. Neural Netw. 2013;39:52.

167. Yazdanbakhsh A, Gori S. Mathematical analysis of the accordion grating illusion: a differential geometry approach to introduce the 3D aperture problem. Neural Netw. 2011;24(10):1093-101.

168. Green CS, Pouget A, Bavelier D. Improved probabilistic inference as a general learning mechanism with action video games. Curr Biol. 2010;20(17):1573-9.

169. van Ravenzwaaij D, Boekel W, Forstmann BU, Ratcliff R, Wagenmakers EJ. Action video games do not improve the speed of information processing in simple perceptual tasks. J Exp Psychol Gen. 2014;143(5):1794-805.

170. Li R, Polat U, Makous W, Bavelier D. Enhancing the contrast sensitivity function through action video game training. Nat Neurosci. 2009;12(5):549-51.

171. Sperling AJ, Lu Z, Manis FR, Seidenberg MS. Deficits in perceptual noise exclusion in developmental dyslexia. Nat Neurosci. 2005;8(7):862-3.

172. Bejjanki VR, Zhang R, Li R, Pouget A, Green CS, Lu ZL, et al. Action video game play facilitates the development of better perceptual templates. Proc Natl Acad Sci U S A. 2014;111(47): 16961-6.

173. Watanabe T, Náñez JE, Sasaki Y. Perceptual learning without perception. Nature. 2001;413(6858):844-8.

174. Seitz AR, Watanabe T. Psychophysics: is subliminal learning really passive? Nature. 2003;422(6927):36.

175. Seitz AR, Watanabe T. The phenomenon of task-irrelevant perceptual learning. Vision Res. 2009;49(21):2604-10.

176. Seitz AR, Protopapas A, Tsushima Y, Vlahou EL, Gori S, Grossberg S, et al. Unattended exposure to components of speech sounds yields same benefits as explicit auditory training. Cognition. 2010;115(3):435-43.

177. Kim YH, Kang DW, Kim D, Kim HJ, Sasaki Y, Watanabe T. Realtime strategy video game experience and visual perceptual learning. J Neurosci. 2015;35(29):10485-92. This study consists in an examination of how video game experience could influence visual perceptual learning performance.

178. Erickson KI, Boot WR, Basak C, Neider MB, Prakash RS, Voss MW, et al. Striatal volume predicts level of video game skill acquisition. Cereb Cortex. 2010;20(11):2522-30.

179. Helie S, Chakravarthy S, Moustafa AA. Exploring the cognitive and motor functions of the basal ganglia: an integrative review of computational cognitive neuroscience models. Front Comput Neurosci. 2013;7:174.

180. Pernet CR, Poline JB, Demonet JF, Rousselet GA. Brain classification reveals the right cerebellum as the best biomarker of dyslexia. BMC Neurosci. 2009;10:67.

181. Tettamanti M, Moro A, Messa C, Moresco RM, Rizzo G, Carpinelli A, et al. Basal ganglia and language: phonology modulates dopaminergic release. Neuroreport. 2005;16(4):397-401.

182. Soriano-Mas C, Pujol J, Ortiz H, Deus J, López-Sala A, Sans A. Age-related brain structural alterations in children with specific language impairment. Hum Brain Mapp. 2009;30(5):1626-36.

183. Vicari S, Marotta L, Menghini D, Molinari M, Petrosini L. Implicit learning deficit in children with developmental dyslexia. Neuropsychologia. 2003;41(1):108-14. 
184. Lum JA, Ullman MT, Conti-Ramsden G. Procedural learning is impaired in dyslexia: evidence from a meta-analysis of serial reaction time studies. Res Dev Disabil. 2013;34(10):3460-76.

185. Ullman MT, Pierpont EI. Specific language impairment is not specific to language: the procedural deficit hypothesis. Cortex. 2005;41(3):399-433.

186. Nicolson RI, Fawcett AJ. Long-term learning in dyslexic children. Eur J Cogn Psychol. 2000;12(3):357-93.

187. Tanaka SC, Doya K, Okada G, Ueda K, Okamoto Y, Yamawaki S. Prediction of immediate and future rewards differentially recruits cortico-basal ganglia loops. Nat Neurosci. 2004;7:887-93.

188. Lo CC, Wang XJ. Cortico-basal ganglia circuit mechanism for a decision threshold in reaction time tasks. Nat Neurosci. 2006;9(7): 956-63.
189. Boot WR, Blakely DP, Simons DJ. Do action video games improve perception and cognition? Front Psychol. 2011;2:226.

190. Kraus N, Nicol T. The cognitive auditory system: the role of learning in shaping the biology of the auditory system. in: Popper AN, Fay RR, editors. Perspectives on auditory research. Springer Handbook of Auditory Research; 2014. 50, pp. 299-319.

191. Tierney A, Kraus N. Music training for the development of reading skills. In: Merzenich MM, Nahum M, Van Vleet TM, editors. Progress in brain research, vol. 207. Burlington: Academic; 2013. p. 209-41.

192. Bhide A, Power A, Goswami U. A rhythmic musical intervention for poor readers: a comparison of efficacy with a letter-based intervention. Mind Brain Educ. 2013;7(2):113-23. 